\title{
Applying Precautionary Principle in Fisheries Management
}

\author{
Emmy Latifah ${ }^{\star}$; Moch Najib Imanullah ${ }^{\star \star}$ \\ * Faculty of Law, Sebelas Maret University. \\ emmylatifah@staff.uns.ac.id

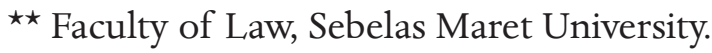 \\ imanulahnajib@yahoo.com
}

\begin{abstract}
The aim of this paper is to examine an applying the precautionary principle in fisheries management. Precautionary principle is a principle where the possibility exist of serious or irreversible harm, lack of scientific certainty should not preclude cautions action by decision-makers to prevent or mitigate such harm. This principle has been accepting in widely international environmental law so that with applying this principle in fisheries management, it could be expected to provide an opportunity to progress towards sustainable fisheries development.
\end{abstract}

Keywords: Precautionary Principle, Fisheries Management.

\section{A. Introduction}

Generally, there are five matters threating the life and sustainability of marine ecosystem. ${ }^{1}$ They are: (1) climate change as a result of rising carbon dioxide level at atmosphere so that it has been resulting in rising ocean temperatures, acidity, pattern of water movement (in-

1 John Nevill, "Threats to Marine Biodiversity", www.onlyoneplanet.com/ marineBiodiversity Threats.doc, accessed on 2 January 2018. 
cluding currents, eddies, and fronts), storminess and sea level, as well as impacts from damage to the ozone layer; (2) overfishing with attendant bycatch ${ }^{2}$ problems, both from industrial fishing, recreational fishing, illegal, unregulated, and unreported fishing (IUU), and ghost fishing; (3) habitat damage, including destruction of coral reefs, mangroves, natural freshwater flows (and passage), coastal foreshores, coastal wetlands, which largely caused by fishing gear (bottom trawling); (4) pollution: including nutrients, sediments, plastic litter, noise, hazardous and radioactive substances; discarded fishing gear, microbial pollution, and trace chemicals such as carcinogens, endocrinedisruptors, and info-disruptors; and (5) ecosystem alterations caused by the introduction of alien organisms, especially those transported by vessel ballast water and hull fouling.

Among these five matters, fishing has been the most damaging on a global scale. The destructive impacts of fishing stem chiefly from overharvesting, habitat destruction, and bycatch. Nowadays, modern fishing activities constitute the most important threat to marine ecosystem.

In order to prevent the massive damage of fisheries, it should be conducted by applying the precautionary principle. The wide adoption of this principle could change drastically the state of affairs in marine living resources conservation and could offer an opportunity to improve fisheries management and ensure sustainable fisheries development.

The aim of this paper is to review an applying the precautionary principle in fisheries management.

2 There are some definitions of by catch accepted by international community. One of definition given by OECD reveal that bycatch is total fishing mortality excluding that accounted directly by the retained catch of target species. This definition thus includes fish which die as a result of interaction with the fishing gear, even if they do not leave the water and could include fish which die as a result of "ghost fishing", it is a capture of fish in the water by lost or abandoned fishing gear. More detail, see OECD, Toward Sustainable Fisheries: Economic Aspects of Management of Living Marine Resources, OECD Publication, Paris, 1997, p. 13. 


\section{B. The Concept of Precautionary Principle and Its Recognition in International Fora}

The development of precautionary principle began when it has been featured as a principle in West Germany's legal system. ${ }^{3}$ Principally, it provides guidance in the management of environmental decisions, where there is scientific uncertainty.

There is no uniform understanding of the meaning of the precautionary principle among the States and other members of international community. ${ }^{4} \mathrm{~A}$ basic definition of this principle is "... where the possibility exist of serious or irreversible harm, lack of scientific certainty should not preclude cautions action by decision-makers to prevent or mitigate such harm." 5 From many definitions, this principle has two key elements. First, that an expression of a need by decision-makers to anticipate harm before it occurs. Within these elements lies an implicit reversal of the burden of proof. Under the precautionary principle, it is the responsibility of an activity proponent (e.g.: someone wishing to harvest fish) to establish that the proposed activity will not (or is very unlikely to) result in significant harm. ${ }^{6} \mathrm{Sec}$ ond, the establishment of an obligation, if the level of harm may be high, for action to prevent or minimize such harm even when the absence of scientific evidence makes it difficult to predict the likelihood of harm occurring, or to predict the level of harm should it occur. The need for precautionary control measures increase with both the

3 The Federal Republic of Germany has been a pioneer in formulating the precautionary principle (it called "vorsorgeprinzip") in their national environmental law in 1974. For detail, see A. Nollkaemper, "The Precautionary Principle in International Law”, Mur. Pollut. Bull., Vol. 22, Issue 3 (1999), p. 107-110.

4 Simon Marr, “The Southern Bluefin Tuna Cases: The Precautionary Approach and Conservation and Management of Fish Resources”, EJIL (2000), Vol. 11 No. 4, p. 821.

5 John Nevill, Op.Cit.

6 Rosie Cooney, "The Precautionary Principle in Biodiversity Conservation and Natural Resource Management: An Issue Paper for Policy-maker, Researchers, and Practitioners," IUNC Policy and Global Change Series No. 2, IUNC, The World Conservation Union, 2004, p. 5-8. 
level of possible harm and the degree of uncertainty.

Moreover, a traditional interpretation reveals that the precautionary principle requires activities and substances which may be harmful to the environment to be regulated, and possibly prohibited, even if no conclusive or overwhelming evidence is available as to the harm or likely harm they may cause to the environment. ${ }^{8}$ The most advanced approach shifts the burden of proof which currently lies with the person opposing an activity to prove that it does or may cause environmental damage. It would require the person who wishes to carry out an activity to prove that it will not cause harm to the environment. ${ }^{9}$

A distinction exists between the precautionary principle and the precautionary approach. As Garcia pointed out, the wording of "the approach" largely similar to that of "the principle", is subtly different in that: (1) it recognizes that there may be differences in local capabilities to apply the approach; and (2) it calls for cost-effectiveness in applying the approach, e.g. taking economic and social cost into account. "The approach" is generally considered a softening of "the principle". ${ }^{10}$

The most widely known definition of the precautionary principle can be ascribed to the 1992 Rio Declaration. Principle 15 of the Declaration states that:

"....in order to protect the environment, the precautionary approach shall be widely applied by States according to their capabilities. Where there are

7 Simon Marr, Op.Cit.

8 The traditional interpretation could be seen within Article 7 of the 1990 Bergen Ministerial Declaration; Article 15 of the 1992 Rio Declaration; Article 4(1)(f) of the 1992 Climate Change Convention; and Article 14(1)(a) of the 1992 Convention on Biological Diversity.

9 The most uncompromising application of the precautionary principle established in the 1952 International Convention for High Seas Fisheries of the North Pacific Ocean, which provided "the abtention principle". For more detail, see Freestone, "Implementing Precaution Cautiously", in Ellen Hey (ed.), Changing International Fisheries Law (1999), p. 287-325.

10 S.M. Garcia, "The Precautionary Approach to Fisheries and Its Implications for Fishery Research, Technology, and Management: An Updated Review”, paper presented in Conference on Tech. Consultation on the Precautionary Approach to Capture Fisheries, Sweden, 6-13 Jun, 1995. 
threats of serious or irreversible damage, lack of full scientific certainty shall be not used as a reason for postponing cost-effective measures to prevent environmental degradation. ${ }^{11}$

Similarly, the 1992 Framework Convention on Climate Change obliges participating parties "to take precautionary measures to anticipate, prevent or minimize the causes of climate change and mitigate its adverse effects. Where there are threats of serious or irreversible damage, lack of scientific certainty should not be used as a reason for postponing cost-effective measures". ${ }^{12}$ The term "approach" instead of "principle" is used in the preamble of the 1992 Convention on Biological Diversity: “...where there is a threat of significant reduction or loss of biological diversity lack of full scientific certainty should not be used as a reason as postponing measures to avoid or minimize such a threat". ${ }^{13}$ The United Nations Program for Further Implementation of Agenda 21 speaks of progress made "incorporating principles contained in the Rio Declaration...including...the precautionary principle”. ${ }^{14}$

\section{The Concept of Fisheries Management}

There is no clear and generally accepted definition of fisheries management. FAO gives the definition of management fisheries as:

"...the integrated process of information gathering, analysis, planning, consultation, decision-making, allocation of resources and formulation and implementation, with enforcement as necessary, of regulations or rules which govern fisheries activities in order to ensure the continued productivity of the resources and the accomplishment of other fisheries objectives."

From this definition, it can be seen that fisheries management entails a complex and wide-embracing set of tasks, aimed at ensur-

11 UN Rio Declaration on Environment and Development. A/CoNF.151/26. Vol. I.

12 Framework Convention on Climate Change (May 9, 1992). 31 ILM 849. Art. 3 para. 3.

13 United Nations Convention on Biological Diversity. 31 ILM (1992). Preamble, 9.

14 UN Program for Further Implementation of Agenda 21. Resolution S / 19-2. para. 14. 
ing that the optimal benefits are obtained for the local users, State or region from the sustainable utilization of the living aquatic resources to which they have access. While fisheries management draws on fisheries research and analysis and, sometimes, institutionalized processes of elaboration of advice, it should not be confused with them; it encompasses but goes beyond them. From the working definition above, fisheries management can be taken to include the following:

a. Setting policies and objectives for each fishery or stock to be managed, taking into account the biological characteristics of the stock, the nature of existing or potential fisheries and other activities related to or impacting the stock and the potential economic and social contribution of the fishery to national or local needs and goals.

b. Determining and implementing the actions necessary to enable the management authorities, the fishers and other interest groups, to work towards the identified objectives. This task should be done in consultation with all interest groups. The actions required will include: developing and implementing management plans for all managed stocks; ensuring that the stock or stocks, the ecosystems in which they occur and their environment are maintained in a productive state; collecting and analyzing the biological and fishery data necessary for assessment, monitoring, control and surveillance; adoption and promulgation of appropriate and effective laws and regulations necessary to achieve the objectives, and ensuring that fishers comply with them to achieve the objectives.

c. Consulting and negotiating with users or interest groups concerned with resources and from areas not directly related to fishery activities but which impact on fisheries. Examples would include groups engaged in activities in a river or lake basin or the coastal zone which impactonfisheries. The management authority needs to ensure that the interests of fisheries are appropriately considered and catered for in planning and integration of such activities.

d. In consultation with the users, regularly reviewing the 
management objectives and measures to ensure they are still appropriate and effective.

e. Reporting to Governments, users and the public on the state of resources and management performance.

There has been a lot of interest in recent years in moving from fisheries management focused essentially on single-species or single fisheries, to ecosystem-based management with an ecosystem orientation. This expanded approach has been termed ecosystem-based fisheries management (EBFM) and was recently discussed at "The Reykjavik Conference on Responsible Fisheries in the Marine Ecosystem" at 1-4 October 2001, which was organized jointly by FAO and the Governments of Iceland and Norway. The Conference agreed on the Reykjavik Declaration which included an affirmation "that incorporation of ecosystem considerations implies more effective conservation of the ecosystem and sustainable use" and also a reaffirmation of the principles of the FAO Code of Conduct for Responsible Fisheries.

\section{Applying Precautionary Principle in Fisheries Management}

a. Rationale for applying precautionary principle in fisheries management

An attention from international community over the fishing practices and fisheries management began to rise in the latter half of the nineteenth century. Decreasing of major fisheries demonstrated the serious, and in some cases irreversible, environmental effects of overfishing and the severe economic consequences for fishing industries. Significant uncertainty, including fish stocks, the marine environment, and the impacts from fishing, hindered the development of appropriate management arrangements and contributed to fisheries collapses. The Canadian Northwest Atlantic Cod fishery for instant, collapsed in 1992. Regarded to this matter, Food and Agriculture Organization (FAO) stated that "a large proportion of the world's exploited fish stocks are fully exploited, over-exploited, depleted or in need of recovery... Major 
ecological damage, which may not always be reversible, and economic waste are already evident in many cases" 15

Some uncertainties would remain due to the complexity of marine ecosystem, and time lags and difficulties in obtaining relevant scientific information. ${ }^{16}$ Lack of relevant scientific knowledge, combine with the potential for serious or irreversible environmental damage, suggests that precaution may be warranted. The FAO concluded that "most problems affecting the fisheries sector result from insufficiency of precaution in management regimes when faced with high levels of uncertainty." ${ }_{17}$ Precautionary provisions were incorporated into international fisheries agreements and policies from the mid-1990s.

b. Uncertainty in fisheries management

Making decision on how best to manage fisheries, involve an element of risk in that there could be negative and unintended consequences from decisions. ${ }^{18}$ Risks are the odds based on the past experiences that some event could be happened, even though it could not be predicted exactly what will happen in the future. ${ }^{19}$ FAO notes that risks are the probability of something undesirable happening. ${ }^{20}$ Furthermore, FAO also differentiates between risks and expected loss or average forecasted loss. ${ }^{21}$ Risks come from

15 FAO, "FAO Technical Guidelines for Responsible Fisheries," No. 4, Rome, 1997 , p. 6.

16 Elizabeth A. Fulton, Anthony D.M. Smith, David C. Smith, Ingrid E. van Putten, "Human behavior: the key source of uncertainty in fisheries management”, Fish and Fisheries, Vol. 12, Issue 1, March 2011, p. 2-

17 FAO, "Precautionary Approach to Capture Fisheries and Species Introductions,” FAO, Roma, 1996, p. 3, http://www.fao.org/3/a-w3592e.pdf, Accessed at 10 January 2018.

18 Dave Mac Neill, "Understanding Risks and Uncertainties in Fisheries,” New York Sea Grant, Oswego, without year, p. 2. http://www.seagrant.sunysb.edu/glsportfish/pdfs/GLFishUncertainties.pdf, Accessed at 2 January 2018.

19 Ibid.

20 FAO, "Precautionary Approach to Capture Fisheries and Species Introduction,” http: / / www.fao.org/ docrep/003/W3592E/w3592e06.htm\#bm06, Accessed at 2 January 2018.

21 Ibid. 
limited human control of certain situation and lack of information (data) needed to understand the situation in which decisions are made. ${ }^{22}$

There are risks in establishing fishing regulations and fish stocking rates to provide economically viable fisheries and to prevent fish population collapses. ${ }^{23}$ These particular risks are especially troublesome since if they occur, fisheries effects are often either irreversible or extremely difficult to remedy. Within the last 20 years, there has been a shift in decision-making to consider ways to minimize risk, to account for risks and benefits (biological and economic benefits) in developing decisions and to communicate risks to all concerned. ${ }^{24}$

Uncertainty is a term used to describe those situations in which the risks are unknown. ${ }^{25}$ These are the sudden and unexpected events that can appear and really catch off-guard with occasionally catastrophic results. ${ }^{26}$ In these cases, it is not only do not know what will happen the next, but absolutely no information (data) on the risks or odds of it occurring in the first place. ${ }^{27} \mathrm{FAO}$ gives definition of uncertainty is the completeness of knowledge about the state or processes of nature. ${ }^{28}$

Uncertainties originate from biological, economic, and political factors that influence fisheries and interfere with the ability to develop effective management plans. ${ }^{29}$ Managing fisheries under uncertainty has become a top priority for fisheries biologist around the world. Such uncertainties in fisheries, as in all natural resources, stem primarily from these inescapable facts that: (1)

22 Dave Mac Neill, Op.Cit.

23 Ibid.

$24 \mathrm{Ibid}$.

25 Krauss M.P., "Defining uncertainty: a conceptual basis for uncertainty management in model-based decision support", Integrat Ass, Vol. 4, Issue 1, 2003 , p. 5-17.

26 Dave Mac Neill, Loc.cit, p. 3.

27 Ibid.

28 FAO, "Precautionary Approach to Capture Fisheries and Species Introduction", Op.Cit.

29 Dave Mac Neill, Op.Cit. 
nature is seldom very stable and things can change quickly from one time to the next; (2) humans will make mistakes when observing, measuring, or interpreting nature, no matter how careful; (3) the human concepts (or models) used to describe fisheries are like puzzle. Although models can be accurate, they can often be too complex or too simple, incomplete or simply wrong, as there is limited understanding of how many pieces there are, and where or how they fit together; (4) some parts of the natural world are better understood than others. Effective management decisions can be made, but sometimes putting the full plan into action falls short because of circumstances beyond control of fisheries managers; (6) science is an objective process by which information (data) is collected and evaluated so that judgments can be made. How to balance between providing fish to harvest while also conserving the resource, however, is not entirely a science based question.

Moreover, uncertainties in fisheries management stems mainly from seven sources: ${ }^{30}$

1) Imperfect understanding of the oceanographic drivers of ecosystem function and species behavior, reproduction, and growth within ecosystem;

2) Imperfect understanding of species-specific biology, including growth rates and drivers, and movement pattern driven in part by feeding and reproduction;

3) Imperfect understanding of the behavior of species within ecosystems;

4) Imperfect predictive models of species biology and ecosystem function (incorporation the effect of fishing on ecosystems, including bycatch, habitat damage, and the impact of discarding.

5) Errors created by inaccurate or insufficient sampling for stock and other empirical data, which seeks to support

30 Jonathan Nevill, "Overfishing under regulation: the application of the precautionary principle and the ecosystem approach in Australian fisheries management," VDM Verlag, Saarbrucken, 2010, p. 3. 
understanding of the size, movement, growth, mortality, and genetic diversity of stocks of fisheries target and bycatch species, and to provide oceanographic and ecosystem-related information;

6) Systemic but poorly-appreciated bias in scientific advice and managerial decisions resulting from the cultures in which these groups operate; and

7) Imperfect prediction of fisher behavior, including movement, fishing effectiveness, and ecosystem damage (primarily from gear damage, bycatch, and discards).

Uncertainties are challenge to decision maker trying to balance sustainable fisheries, maintaining fishing opportunities for diverse stakeholders for as long as possible, with conserving fish populations. Uncertainties affect the ability to understand the complex mechanisms that drive fish population sizes up and down. Among global fisheries, there are many uncertainties as common questions. These ones are: ${ }^{31}$

1) How many fish are there in the ocean to catch?

2) For how long will these fisheries be sustainable?

3) How does fishing effect these fish populations?

4) How many fish should be stocked?

5) How many survive after stocking? How many fish are produced naturally?

6) How many bait fish are out there to feed the predatory fish?

7) What are the best ways to collect fish to get good information to manage fisheries properly?

8) How do ecosystem changes in the ocean, lakes, and rivers affect their respective fisheries?

9) What are the impacts of invasive species on our fisheries?

10) How will budget issues or changes in political leadership affect fisheries management?

11) How much control do fisheries manager really have in managing fisheries?

31 Dave Mac Neill, Op.Cit. 
In order to face uncertainties in fisheries management, information or data are becoming important factor to balance sustainable fisheries. These data are obtained from sample of fish populations collected over a large geographic area and over time so that data are a representation of what is going on in the fish population and fishery of interest. Further, fisheries data are analyzed using sophisticated techniques to provide estimates of important characteristics of the fish population such as abundance growth (including numbers of fish at each age), diet, habitat, reproductive output, survival, impacts from fishing and interactions with other species (fish and non-fish). ${ }^{32}$

The data are sometimes used to develop the management decisions that are designed to simultaneously protect fisheries through limits on numbers or sizes caught and kept, and to meet diverse stakeholder's interest. ${ }^{33}$ These complex decisions have important biological, economic, and social consequences, often over a very short timeframe. In reality, successful fisheries management depends upon the ability to anticipate the future changes in fisheries, identify risks and uncertainties, identify new management opportunities, as well as to properly monitor progress in reaching fisheries goals. ${ }^{34}$

c. International approach taken by FAO in applying precautionary principle over fisheries management

The need for precautionary management was formally discussed at the 1973 FAO Technical Conference on Fisheries Management and Development. ${ }^{35}$ The first appearance of the precautionary principle in international law was in 1982, when a version of the principle was formulated in The World Charter for Nature, a resolution of the United Nations General Assembly. Importantly, it was later incorporated in the FAO Code of Conduct

32 Ibid.

33 Ibid.

34 Ibid.

35 J.F. Caddy and K. L. Cochrane, "A Review of Fisheries Management Pas and Present and Some Future Perspectives for the Third Millenium”, Ocean and Coastal Management, Vol. 4, Issue 9-10, 2001, p. 659 (653-682). 
for Responsible Fisheries 1995, leading to inclusion in the United Nation Agreement on the Conservation and Management of Straddling Fish Stocks and Highly Migratory Fish Stocks and the subsequent development of FAO guidelines for the application of the principle. This guideline is more fully developed for the fishing sector than for any other industrial sectors.

FAO has drawn up guideline which is provided frameworks on how to conduct fishery management and research in the context of uncertainty. Specific guideline identifies the ways to address uncertainty and apply precautionary approach (FAO use the term of "precautionary approach" than "precautionary principle"), such as the identification of possible scenarios and development of contingency plans and decision rules for responding to unexpected or unpredictable events.

An important element of the precautionary approach is to establish legal or social management frameworks for all fisheries, which is not the current situation. ${ }^{36}$ At a minimum, such framework should establish rules controlling access to fisheries, data reporting requirements, and processes for planning and implementing more comprehensive fisheries management. ${ }^{37}$ Plans for management institutionalize prudent foresight that takes into account potential consequences of fishery development and events affecting it. ${ }^{38}$ Comprehensive plans for fisheries can take a long time to develop. For this reason, the legal and social management framework should include interim measures that safeguard the resources until such plans are adopted. ${ }^{39}$

Management according to the precautionary approach exercises prudent foresight to avoid unacceptable or undesirable situ-

36 S.M. Garcia, “The Precautionary Principle: Its Implications in Capture Fisheries Management”, Ocean and Coastal Management, Vol. 22, 1994, p. 99125.

37 Ibid.

38 Ibid.

39 FAO, "Precautionary Approach to Fishery Management," http: / / www.fao. org/docrep/003/w3592e/w3592e07.htm\#TopOfPage, Accessed at 2 January 2018. 
ations, taking into account that changes in fisheries systems are only slowly reversible, difficult to control, not well understood, and subject to change in the environment and human values. ${ }^{40}$ Precautionary management involves explicit consideration of undesirable and potentially unacceptable outcomes and provides contingency and other plans to avoid or mitigate such outcomes. Undesirable or unacceptable outcomes include overexploitation of resources, overdevelopment of harvesting capacity, loss of biodiversity, major physical disturbance of sensitive biotopes, or social or economic dislocations. Undesirable conditions can also arise when a fishery is negatively influenced by other fisheries or other activities and when management fails to take action in the face of shifts in the external conditions affecting, for example, the productivity of the fish stocks.

The precautionary approach is included in all stages of the management process, begin from planning, implementation, enforcement, monitoring until re-evaluation..$^{41}$

i. Management planning

A precautionary approach to managing fishery involves developing, within management strategies and plans, explicit consideration of precautionary actions that will be taken to avoid specific undesirable outcomes, a management plan should include mechanisms to monitor and control that capacity. Consideration needs to be given to how uncertainty and ignorance are to be taken into account in developing and varying management measures. For all fisheries, plans should be developed or revised to incorporate precautionary elements. The plans will also be required to implement precautionary approaches to fisheries aggregate impact on the marine environment. The plans should take into account the time scales, at least two to three decades, or longer in the case of long-lived species.

The plans including determine: (1) specific management objectives; (2) specific operational targets and constrains; (3) specific 
procedure to apply and adjust management measures; and (4) prospective evaluation.

a) Determine the specific management objective

The management objectives need to consider both the manner in which the benefits from the fishery are to be realized, as well as the possible undesirable outcomes which are to be avoided. Broad objectives include considerations of long-term interests and the avoidance of irreversible or slowly reversible changes. Typically, the catches are to be as large as possible, so long as the probability of substantial stock depletion is below an acceptably low level and catches can be kept reasonably steady. The general objectives could be taken as the starting point for setting the more specific objectives for a particular fishery. To be precautionary, priority should be accorded to restoration of already overfished stocks, to avoidance of overfishing, and to avoidance of excessive harvesting capacity. Objectives should also include restricting the environmental impacts of fishing to acceptable levels. Some examples are limiting or eliminating bycatch and incidental mortality of non-target species and containing the possible effects of some types of fishing gear on bottom communities.

b) Determine the specific operational target and constrains

Regarding to determine the targets, it could be conducted by identifying the desired outcomes for the fishery. These may take the form of a target fishing mortality or a specified level of average abundance relative to the unfished state. In some cases, these targets are likely to be identical with those that would be specified for fisheries management, regardless of whether a precautionary approach to be adopted. In other cases, targets may need to be adjusted to be precautionary, for example, by setting the target fishing mortality lower than maximum sustainable yield (MSY). ${ }^{42}$

42 Theoretically, Maximum Sustainable Yield (MSY) is the largest yield (catch) that can be taken from a specific fish stock over an indefinite period under constant environmental conditions. It is measured in tonnes. For detail in- 
Explicitly, constraints are the undesirable outcomes that are to be avoided. For example, in order to avoid the risk of declining recruitment, a minimum spawning stock biomass, range of ages, or geographic range could be set to define safe limits within which the stock should be maintained with a specified high probability. Specific limits may also be required to deal with ecosystem effects, with bycatch and with other side-effects of the fishery. Operational targets and constraints should be expressed in measurable terms such as target reference points and limit reference points. The details of what can be measured will often vary with different species and fisheries, and so the operational targets and constraints will need to be expressed in ways that take this into account. The specification of operational targets and constraints cannot be separated from consideration of the types of data and methods that can be used to assess the status of the stocks. In all cases, attention should be given to the rate at which targets are approached so as to avoid overshooting them and hence violating the constraints.

c) Determine specific procedure to apply and adjust management measures

A management plan must indicate that management measures has to be applied and the circumstances under which the measures are to be varied. This should involve the formulation of decision rules, which specify in advance what action should be taken when specified deviations from the operational targets and constraints are observed. The specification should include minimum data requirements for the types of assessment methods to be used for decisionmaking.

A decision could be considered as a precautionary decision when decision rules are required for responding to unexpected

formation regarding this matter, see Carmel Finley, Naomi Oreskes, "Maximum Sustainable Yield: A Policy Disguised as Science," ICES Journal of Marine Science, Vol. 70, No. 2, 2013, p. 247 doi:10.1093/icesjms/fss192. 
or unpredictable events with minimum delay. All foreseeable contingencies should be considered when developing the plan. For example, plans should include explicit effort-reduction measures that apply in response to unpredicted, marked decline in recruitment.

It is highly desirable that the procedure makes regular small adjustments to the management measures so as to maintain acceptably low levels of probability that the constraints are violated. It is not always possible to simultaneously attain a target (desired outcome) for a fishery and respect constraints designed to prevent undesirable outcomes. For example, a specified target fishing mortality such as MSY may reduce the spawning stock biomass to a level near the levels where there should be a precautionary constraint designed to avoid the probability of declining recruitment. If, for example, the constraint is to maintain spawning stock biomass above $30 \%$ of the average unfished level with high probability, then a MSY target that would reduce the spawning stock biomass to $35 \%$ of the unfished level could have a too high probability of violating the constraint. Precautionary management must adjust targets to be consistent with the constraints.

d) Determine prospective evaluation

A precautionary approach requires that the feasibility and reliability of the management options be evaluated. A management plan should not be accepted until it has been shown to perform effectively in terms of its ability to avoid undesirable outcomes. The evaluation can be used to determine whether the data and assessment methods available for management are sufficient to meet the management objectives. The evaluation should attempt to determine if the management plan is robust to both statistical uncertainty and to incomplete knowledge on factors such as uncertain stock identity and abundance, stock dynamics, and the effects of environmental variability and trends. As well, evaluations should consider the dynamic behaviour of the harvesting 
sector and manager ability to change harvest levels.

For economically valuable fisheries, and where substantial scientific expertise is available, there will usually be substantial benefits from employing powerful evaluation techniques such as simulation modelling. Such analyses will often reveal that sources of uncertainty are critical to achieving satisfactory results for the various objectives. The evaluation will also need to take into account the practicality of implementing, and securing compliance with, the range of management measures included in the plan.

ii. Implementation, enforcement, monitoring

Management plan implementation puts in place all planned decision rules. This involves the practical interpretation of objectives and procedures, and the implementation of detailed instructions for compliance, monitoring of the fishery, and enforcement mechanism. Elements of the implementation phase including: stock assessments, rule setting, economic assessments, and communication of decisions and rationale to the public and fishing industry. ${ }^{43}$ Since the public and industry are more inclined to understand and support measures on which they are consulted, public participation in the implementation phase is urgent. Peer review of stock assessments and a transparent process help to guard against error, which is essential to effective implementation of the planned measures. Independent auditing of the monitoring procedures should also be a regular feature of the management system. The effect of the measures on compliance should be studied specifically.

Monitoring of a fishery involves collection of all information relevant to ensuring that the plan is being executed properly and that it is achieving the desired results. Particularly, data are needed to determine whether that precautionary decision rules are being violated. A precautionary approach to monitoring will use many and various sources of information, including environ-

43 FAO, "Precautionary Approach to Fishery Management", Op.Cit. 
mental and socio-economic data.

Precautionary monitoring of fishing should seek to detect and observe a variety of ancillary impacts, such as environmental changes, fish habitat degradation, and effects on birds, mammals and other biota. This monitoring function could use information from fishing participants, indigenous people, and other public groups, and have appropriate procedures to process and analyze this information.

In a precautionary management system, contingency rules should be implemented to ensure compliance with operational targets and constraints in the face of major adverse events with low probability. There should also be mechanisms for revising targets and constraints in the light of unexpected events.

A system of enforcement over precautionary and the penalties for non-compliance should have the flexibility for prompt action by redeployment of monitoring and enforcement resources. For example, the first signs of bycatch problems should be followed by more extensive sampling in problem areas according to an agreed procedure or enhanced surveillance of the fishery. In the case of emergency, it should be possible to rapidly modify regulations.

iii. Evaluation

Evaluation is needed on the level of precaution in the management system periodically. This includes: (1) the degree of precaution in the objectives, operational targets and constraints in relation to observed changes in the fishery and the environment, (2) the use of scientific information and other information in the management process, (3) the applicability of the contingency plans for unexpected conditions, and (4) auditing of all procedures in the fisheries management system. Special evaluations should be initiated as soon as it becomes apparent that the fishery inadvertently violates the limit reference points established in the plan. ${ }^{44}$

44 Ibid. 


\section{E. Conclusion}

The precautionary principle has been progressively more accepted and its field of application has been broadened to include the management of natural renewable resources, including fisheries. This principle is urgent to be applied in fisheries management, which emphasizes the growing awareness that fisheries management cannot be seen in isolation and must fit an integrated context which satisfies the requirement for long-term resources sustainability and environmental conservation.

\section{Bibliography}

Caddy, J.F. and K. L. Cochrane, "A Review of Fisheries Management Pas and Present and Some Future Perspectives for the Third Millenium”, Ocean and Coastal Management, Vol. 4, Issue 9-10.2001.

Cooney, Rosie, 2004, "The Precautionary Principle in Biodiversity Conservation and Natural Resource Management: An Issue Paper for Policy-maker, Researchers, and Practitioners," IUNC Policy and Global Change Series No. 2, IUNC.

FAO, 1997, "FAO Technical Guidelines for Responsible Fisheries," No. 4. Rome: FAO Publication.

FAO, 1996, "Precautionary Approach to Capture Fisheries and Species Introductions," FAO, Roma. http://www.fao.org/3/aw3592e.pdf, Accessed at 10 January 2018.

FAO, "Precautionary Approach to Capture Fisheries and Species Introduction,” http:/ / www.fao.org/docrep/003/W3592E/ w3592e06.htm\#bm06, Accessed at 10 January 2018.

FAO, Precautionary Approach to Fishery Management, http: / www. fao.org/ docrep/003/w3592e/w3592e07.htm\#TopOfPage, Accessed at 2 January 2018.

Finley, Carmel and Naomi Oreskes, 2013, "Maximum Sustainable Yield: A Policy Disguised as Science," ICES Journal of Marine Science, Vol. 70, No. 2, doi:10.1093/icesjms/fss192.

Fulton, Elizabeth A. et al, 2011, "Human Behavior: The Key Source of Uncertainty in Fisheries Management," Fish and Fisheries, 
Vol. 12, Issue 1.

Garcia, S.M., 1995, “The Precautionary Approach to Fisheries and Its Implications for Fishery Research, Technology, and Management: An Updated Review", paper presented in Conference on Tech. Consultation on the Precautionary Approach to Capture Fisheries: Sweden, 6-13 Jun.

Garcia, S.M, 1994, “The Precautionary Principle: Its Implications in Capture Fisheries Management,” Ocean and Coastal Management, Vol. 22.

Hey, Ellen (ed.), 1999, “Changing International Fisheries Law," Alphen aan den Rijn: Kluwer Law International.

Marr, Simon, 2000, “The Southern Bluefin Tuna Cases: The Precautionary Approach and Conservation and Management of Fish Resources,” EJIL, Vol. 11 No. 4.

M.P., Krauss, 2003, "Defining uncertainty: a conceptual basis for uncertainty management in model-based decision support," Integrat Ass, Vol. 4, Issue 1.

Neill, Dave Mac, "Understanding Risks and Uncertainties in Fisheries, New York Sea Grant, Oswego,” http://www.seagrant.sunysb.edu/glsportfish/pdfs/GLFishUncertainties.pdf, Accessed at 2 January 2018.

Nevill, Jonathan, "Threats to Marine Biodiversity,"

www.onlyoneplanet.com/marineBiodiversityThreats.doc, Accessed on 2 January 2018.

Nevill, Jonathan, 2010, "Overfishing under regulation: the application of the precautionary principle and the ecosystem approach in Australian fisheries management," Saarbrucken: VDM Verlag.

Nollkaemper, A, 1999, “The Precautionary Principle in International Law”, Mur. Pollut. Bull., Vol. 22, Issue 3.

OECD, 1997, “Toward Sustainable Fisheries: Economic Aspects of Management of Living Marine Resources”, OECD Publication.

The 1952 International Convention for High Seas Fisheries of the North Pacific Ocean.

The 1990 Bergen Ministerial Declaration. 
Emmy Latifah \& Moch Najib Imanullah

The 1992 Rio Declaration.

The 1992 Climate Change Convention.

The 1992 Convention on Biological Diversity.

UN Framework Convention on Climate Change, 1992.

UN Program for Further Implementation of Agenda 21, 1997.

UN Rio Declaration on Environment and Development, 1992. 